\title{
NUESTRA AMÉRICA COMO PLATAFORMA DE LA EDUCACIÓN EN EL CONTINENTE
}

\author{
Elmys Escribano Hervis ${ }^{1}$ \\ Universidad de Ciencias Pedagógicas - Cuba \\ escriba2003@gmail.com
}

Recepción: 05/12/2011

Evaluación: 03/02/2012

Aceptación: 29/05/2012

Artículo de Revisión

doi: 10,9757

\section{RESUMEN}

En enero de 1891 José Martí publicó el ensayo "Nuestra América", obra esencial de su prosa. Se establece como hipótesis que esta obra es poseedora de una notable significación para la educación y la cultura en Latinoamérica. El objetivo de este trabajo es valorar el ensayo de referencia en estrecha relación con el contexto histórico social que lo condicionó y en consonancia con la integralidad del discurso de su autor. La metodología empleada se sustenta en la revisión, análisis e interpretación de las fuentes bibliográficas disponibles, en este caso la totalidad de la obra escrita de José Martí, ubicada en la edición de 1963, organizadas en 28 tomos. Se trabajó con la edición crítica de este ensayo editada en el año 2000 sobre la base de la investigación y las notas aportadas por CintioVitier. Se concluye que la concepción y escritura de Nuestra América a fines de la penúltima década del siglo XIX, es un hito esencial para el estudio del desarrollo histórico de la educación y la cultura latinoamericanas. Nuestra América convida a hacer causa común con los oprimidos y conceptualiza en el mestizaje, la esencialidad de nuestra cultura. Concibe la educación del hombre natural de América en acomodo con la Naturaleza, con la cultura, con su tiempo y aspiraciones de libertad y desarrollo de nuestras naciones. Es un discurso auténtico y coherente que favorece la determinación de referentes culturales necesarios para la educación del hombre latinoamericano.

Palabras clave: Revista Historia de la Educación Latinoamericana, cultura, educación.

1 Doctor en Ciencias Pedagógicas (1998) Institución de procedencia: Universidad de Ciencias Pedagógicas "Juan Marinello Vidaurreta" Carretera a Cidra, Km. 2. 5. Matanzas. Cuba. Grupo de investigación: Proyecto científico "El empleo de la obra de José Martí en la escuela primaria". 


\section{OUR AMERICA" AS AN EDUCATIONAL PLATFORM IN OUR CONTINENT}

\section{NOSSA AMÉRICA COMO UMA PLATAFORMAPARA A EDUCAÇÃO NO CONTINENTE}

ABSTRACT

In January 1891 Jose Marti published the benchmark of his prose his essay "Our America". The hypothesis stated in this paper identifies that work as a carrier of a great significance for education and culture in Latinoamerica. The purpose of our article is to show the direct link between the social and historical context was written and the thoroughness of Jose Marti's discourse. The methodology used is based on the consulting, analyzing and interpreting available sources; in this case the Complete Works of Jose Marti, as published in 1963, on 28 volumes and the Critical Edition of Jose Marti's work written by CintioVitier. It is concluded that the conception and writing of the essay "Nuestra America" ("Our America") at the end of the eighth decade of the $19^{\text {th }}$ century is an essential landmark for the study of the historic development of Latin-American education and culture. Our America calls for a common cause with the oppressed and it conceptualizes race mixture as the essence of our culture. It conceives education of America's native man in concord with Nature, culture, history and aspirations for freedom as well as the development of our nations on the social basis upon which they were built up. It is an authentic and coherent discourse favoring the determination of a trunk of cultural referents necessary for the education of Latin-American man.

Key words: Journal of Latin American

Education History, culture, education.

\section{RESUMO}

Em janeiro de 1891 José Martí publicou o ensaio "Nossa América" trabalho essencial de sua prosa. Estabelece-se a hipótese de que este trabalho é possuidor de uma grande importância para a educação e cultura na América Latina. O objetivo deste estudo é avaliar o ensaio de referência em íntima relação com o contexto histórico-social que o originou em consonância com a integralidade do discurso do autor. A metodologia é baseada na revisão, análise e interpretação das fontes bibliográficas disponíveis, neste caso, as obras escritas de José Martí, localizado na edição de 1963, organizada em 28 volumes. Nós trabalhamos com a edição crítica deste ensaio publicado em 2000 com base em pesquisas e notas de CintioVitier. Conclui-se que a concepção o escrita de Nossa América, no final da penúltima década do século XIX, é um marco essencial no estudo do desenvolvimento histórico da educação e cultura na América Latina. Nossa América convida para fazer causa comum com os oprimidos e conceituado no mestiçagem, a essêncialidade da nossa cultura. Concebe a educação do homem natural americano em relação com a natureza, com a cultura, com o seu tempo e as suas aspirações de liberdade e desenvolvimento de nossas nações. É um discurso autêntico e coerente, que favorece a determinação de referências culturais necessários para a educação do homem latino-americano.

Palavras-chave: Revista História da Educação Latino-americana, cultura, educaşão.

\section{INTRODUCCIÓN}

El 1ro. de enero de 1891 en la Revista Ilustrada de Nueva York, vio la luz el germinal ensayo de José Martí, "Nuestra América", fue también publicado el 30 de ese propio mes y año en El Partido Liberal, de México. El referido ensayo sintetiza años de estudio minucioso, de aguda observación de las sociedades latinoamericanas, de sus culturas, de sus historias y de sus naturalezas. Conoció y se impresionó de sus héroes, sus artistas y sus poetas. Nada escapó a la acuciosa mirada de quien sus contemporáneos en Nueva 
York, llegaron a llamarle "El Maestro". Es justo que se le reconozca de ese modo, pues tiene este continente una galería de hombres propios de leyendas: tiene Latinoamérica a Simón Bolívar como el "Libertador", tiene a Benito Juárez como el "Benemérito", y tiene en José Martí al "Maestro" y al mismo tiempo al "Apóstol".

El ensayo que se comenta en este trabajo es una expresión legítima de su especial magisterio e indiscutible apostolado. Envueltas en exquisita prosa florida y poética, presentó un análisis de la sociedad Latinoamérica de fines del siglo XIX que se debatía dudosa ante desafíos y peligros, urgida por las circunstancias y el peso de la historia.

La visión martiana resulta una plataforma esencial para el estudio de las problemáticas culturales y educacionales de aquella fecha y de hoy día. El establecimiento de relaciones entre la historia, la cultura y la educación por una parte; y por otra, los proyectos de transformación social esgrimidos hasta le fecha es una lección de incalculable valor que llega hasta hoy día. Su ejercicio de análisis de la realidad de su tiempo, resulta didáctica, aunque por supuesto, él no pretendió hacerlo. "Nuestra América", de José Martí, es la consagración conceptuada de nuestro ser, es el impulso, es el desafío, es la razón de la mano de la fineza y la poesía, es el sueño y el desvelo, es la pasión del ser latinoamericano.

\section{La época y las contradicciones de fin del siglo XIX}

El siglo XIX americano fue un hervidero de ideas, las hubo de las más diversas orientaciones y finalidades. Los distintos proyectos de transformación social se nutrieron de esa complejidad que se acentuó muy especialmente en la segunda mitad del mencionado siglo. Después de concluido el proceso de independencia de las colonias en América Latina, encontrar una ruta hacia el desarrollo y la consagración total de las libertades del hombre fue uno de los más caros anhelos en los que se comprometieron los más ilustres pensadores. En el fragor de este proceso, entró el positivismo al continente favorecido por una tendencia política de orientación liberal. El lema de "orden y progreso" parecía una justa solución en países donde el estancamiento y la esclerosis colonial lastraban el ansiado desarrollo.

Se entró con fuerza una tesis cuestionadora de la capacidad racional del hombre natural de estas tierras y sus posibilidades de enfrentar el gobierno y el desarrollo de forma autónoma e independiente. Al auxilio de estas posiciones recurrían posturas racistas, biologicistas y en un punto más extremo y por 
ende más radical, aplicaron a la sociedad una lectura calenturienta de las teorías de Charles Darwin.

Para asumir con prontitud la meta del desarrollo, las oligarquías criollas que se hicieron con el poder, apelaron a la imitación de la vieja y culta vida europea, especialmente su expresión francesa por una parte, y por otra, algunos pensaron que copiar del industrioso Estados Unidos reportaba la solución al problema americano. El sector social que marchó a la cabeza de los cambios de aquel momento, se pronunció en nombre de la civilización contra las razas inferiores, las que consideraban taradas y salvajes.

Domingo Faustino Sarmiento escribió en Chile la obra "Facundo", en ella se refleja los acontecimientos en Argentina desde la independencia, donde tenía lugar la contradicción "[...]entre la civilización (refugiada en las ciudades, potencial de orden y progreso) y el medio pampeano, cuyos rudos habitantes (los gauchos) eran la manifestación viva del desorden ciego de la naturaleza. La esperanza transformadora de Argentina se identificaba con un programa de reconstrucción nacional, educativo, que salvase el abismo entre la sociedad civilizada y la que se había forjado al margen de ella en las provincias, la gauchada. (Sarmiento intentó, además, aplicar ese programa durante su mandato presidencial, en el período 1868-1874)"'2.

Del pensamiento y la pluma de Sarmiento surgieron infamantes ideas racistas, pues para él América es: "toldos de razas abyectas, un gran continente abandonado a los salvajes incapaces de progreso." 3 Y por si fuera poco lo anterior, "Para nosotros Colocolo, Lautaro y Caupolicán, no obstante los ropajes nobles y civilizados (con) que los revistiera Ercilla, no son más que unos indios asquerosos, a quienes habríamos hecho colgar ahora, si reapareciesen en una guerra de los araucanos contra Chile, que nada tiene que ver con esa canalla"4.

José Martí se opuso a la tesis de Sarmiento acerca de las contradicciones entre civilización y barbarie, dejó bien sentado que "No hay batalla entre la civilización y la barbarie, sino entre la falsa erudición y la naturaleza". Si nos atenemos a Martí, las ideas de Sarmiento, son expresión de una visión colonialista de la sociedad y la historia. Para el Apóstol “... la civilización, que es el nombre vulgar con que corre el estado actual del hombre europeo, tiene derecho natural de apoderarse de la tierra ajena perteneciente a la barbarie,

\footnotetext{
Mentor Interactivo Enciclopedia de Ciencias Sociales. Barcelona (España). Edit. Océano. (s. a.), 227. Roberto Fernández Retamar, Todo Calibán (La Habana, Fondo Cultural del ALBA,2006), 50.

Roberto Fernández Retamar, Todo Calibán 51.

José Martí Pérez, Obras Completas (La Habana, Edit. Nacional de Cuba, 1963),T. VI, 17.
} 
que es el nombre que los que desean la tierra ajena dan al estado actual de

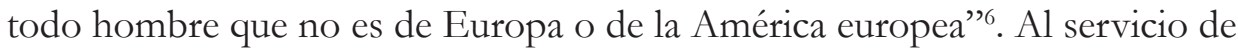
los empeños coloniales emergen teorías para justificar el despojo. ${ }^{7}$ Algunos argumentaron la incapacidad de ciertas razas para gobernarse, además de escribir sobre su abierta tendencia al vicio y la holganza, según esa lógica el problema sería genético y era entonces necesario poblar el continente de razas superiores y racionales, capaces de encauzar la industria, la agricultura y el comercio ${ }^{8}$.

Dicho de una manera simple y quizá esquemática, despojarse de sí para ser como otros, o por el contrario, aferrarse a la autoctonía, a la creación y a la legitimidad de nuestra cultura como posibles rutas viables a la libertad y al desarrollo, eran dilemas esenciales que se planteaban en la época?.

\section{La percepción del hombre en Nuestra América}

Uno de los méritos de Nuestra América, lo es sin dudas el haber desarrollado una tesis para el desarrollo social, cultural, político y educativo anclada en el reconocimiento claro de la esencia del hombre que habita estas tierras. Fue común por la fecha el debate de ideas sobre el hombre y el problema de las razas. Ante los que argumentaban ideas racistas, Martí sostuvo: "Peca contra la humanidad, el que fomente y propague la oposición y el odio de las razas"10. Aseguró que "No hay odio de razas, porque no hay razas. Los pensadores canijos, los pensadores de lámparas, enhebran y recalientan las razas de librería, que el viajero justo y el observador cordial buscan en vano en la justicia de la Naturaleza, donde resalta en el amor victorioso y el apetito turbulento, la identidad universal del hombre" 11 . La idea de las razas había aportado supuestos argumentos justificativos del injusto orden de cosas, primero en la colonia y posteriormente en la república, de ahí el fariseísmo

$\overline{6}$ O. C. Edit Cit. T. VIII, 442.

7 Este fragmento de "Las ruinas indias" resulta ilustrativo: "La superstición y la ignorancia hacen bárbaros a los hombres en todos los pueblos. Y de los indios han dicho más de lo justo en estas cosas los españoles vencedores, que exageraban o inventaban los defectos de la raza vencida, para que la crueldad con que la trataron pareciera justa y convincente al mundo.” José Martí Pérez, $L a$ Edad de Oro (La Habana: Edit. Gente Nueva, S. A.), 85.

8 Juan Bautista Alberdi. Ideas para presidir la confección del curso de Filosofía contemporánea. En: Pensamiento positivista latinoamericano. Tomo I. Compilación. Prólogo y cronología Leopoldo Zea. Caracas: Biblioteca Ayacucho. 1980: 61 - 67.

9 Leopoldo Zea. "La Cultura latinoamericana y su sentido libertario". En Problemas 4. Identidad latinoamericana. Enfoques filosófico - literarios. Sel. Enrique Ubieta Gómez. La Habana: Ed. Academia, 1994.

10 José Martí Pérez, Nuestra América. (La Habana: Edición crítica. Investigación, presentación y notas Cintio Vitier, Centro de Estudios Martianos, 2000), 29.

11 José Martí Pérez, Nuestra América, 28-29. 
de que unas "razas inferiores" debían ser gobernadas por gente "laboriosa y emprendedora". La condición de inferioridad se pagaba con obediencia y sometimiento.

Martí sostuvo la idea de la identidad del hombre. Admitió la existencia de las diferencias dentro de la identidad que se manifiestan condicionadas por la tierra en que se vive. En relación al tema, ya había escrito para los niños del continente en 1889 en "La historia del hombre contada por sus casas": "Estudiando se aprende eso: que el hombre es el mismo en todas partes, y aparece y crece de la misma manera, y hace y piensa las mismas cosas, sin más diferencia que la de la tierra en que vive $[. . .]^{\prime 12}$. De la particularidad de la forma que manifieste la relación el hombre con la naturaleza, con su medio y el modo en que exprese su historia de vida y desarrollo viene dada la singularidad de su cultura. En la obra ya citada de "La Edad de Oro", se extrae esta reflexión: “[...] el hombre que nace en tierra de árboles y de flores piensa más en la hermosura y el adorno, y tiene más cosas que decir, que el que nace en una tierra fría, donde ve el cielo oscuro y su cueva en la roca. Y otra cosa se aprende, y es que donde nace el hombre salvaje, sin saber que hay ya pueblos en el mundo, empieza a vivir lo mismo que vivieron los hombres de hace miles de años"13.

En Martí la concepción del hombre va unida estrechamente a la naturaleza. Las formas y matices que adquiere la vida y la cultura está signada por las relaciones Hombre-Naturaleza. En la naturaleza está también el hombre, está el espíritu que es esencia del hombre. Vivir en armonía con la naturaleza, le reporta al hombre condiciones favorables para su desarrollo pleno y para la expresión en toda su magnitud de la cultura. En el discurso en la Sociedad Literaria Hispanoamericana, el 19 de diciembre de 1889, expresó "[...] nuestra América capaz e infatigable. Todo lo conquista, de sol en sol, por el poder del alma de la tierra, armoniosa y artística, creada de la música y beldad de nuestra naturaleza, que da su abundancia a nuestro corazón y a nuestra mente la serenidad [...]"14.

Martí identificó en Nuestra América la expresión social en el continente de lo que llamó "criollo exótico" para designar a aquellos nacidos en esta parte del mundo que intentaban un camino de desarrollo ajeno a nuestra naturaleza, a nuestra cultura y a nuestra historia. Para ellos el paradigma del progreso en todos los órdenes estaba en otros lugares de la geografía terrestre. Aparece también el denominado "letrado artificial" que practica la lectura estéril, indigesta y copiadiza, haciendo gala de una erudición falsa

\footnotetext{
José Martí Pérez, La Edad de Oro (Edit. Cit. s. a.), 62.

José Martí Pérez, La Edad de Oro.

José Martí Pérez, O. C. (Edit. Cit. 1963),T. VI. 139.
} 
anclada en siglos de cultura europea, en sus leyes, en sus filosofías, en sus valores y modos de interpretar el mundo, un mundo -según esa visión- en el que solo lograríamos alcanzar la condición de patio trasero. Ante el "criollo exótico" o el "letrado artificial", aparece en franca oposición el "hombre natural", el "hombre real", como expresión de una época real que anuncia el cambio. El conocimiento de la base social con la que se hizo la revolución de independencia del pesado lastre del colonialismo, la historia y la cultura de los hombres autóctonos de estas tierras y su naturaleza marcan el sentido del momento "... el libro importado ha sido vencido en América por el hombre natural. Los hombres naturales han vencido a los letrados artificiales. El mestizo autóctono ha vencido al criollo exótico" ${ }^{15}$.

La visión martiana de este fenómeno es crítica e inconforme al mismo tiempo que se presenta optimista del futuro y de la potencialidad creadora del hombre natural y en especial de los jóvenes. "Los jóvenes de América se ponen la camisa al codo, hunden las manos en la masa, y la levantan con la levadura de su sudor. Entienden que se imita demasiado, y que la salvación está en crear. Crear es la palabra de pase de esta generación”"16.

Advierte un período de transición, hay señales de cambios favorables, ya se lee para aplicar, se crea y se aprecia los temas propios sin la tutela del libro yankee o el europeo. "Cansados del odio inútil, de la resistencia del libro contra la lanza, de la razón contra el cirial, de la ciudad contra el campo, del imperio imposible de las, castas urbanas divididas sobre la nación natural, tempestuosa o inerte, se empieza, como sin saberlo, a probar el amor" ${ }^{17}$. Una lectura deficiente de la historia llevó a los caudillos latinoamericanos en el período posterior a las revoluciones de independencia concebir la sociedad como una prolongación de la colonia.

\section{La historia y la sociedad}

El ensayo de referencia muestra una peculiar visión de la historia. Reconoce nuestros orígenes signados por la mezcla entre hombres y mujeres provenientes de pueblos y culturas diferentes. La mirada martiana al proceso histórico reconoce el liderazgo fundador del padre Miguel Hidalgo, Simón Bolívar y José de San Martín, que imbuidos en hábitos monárquicos y señoriales, fueron sensibles a la ideas de la enciclopedia, asimismo, Bolívar el hacendado más rico de Caracas emprendió la lucha contra los demonios del

\footnotetext{
José Martí Pérez, Nuestra América. (Edit. Cit. 2000), 15.

José Martí Pérez, Nuestra América, 24

José Martí Pérez, Nuestra América, 23-24.
} 
colonialismo a lomo de caballo con unos cuantos generales y muchos pobres como ejército.

La historia de tres siglos de práctica colonial, gobiernos despóticos y divorciados del hombre autóctono y de la naturaleza, de racismo y segregación tienen un peso considerable en la conciencia de los hombres del continente y esto se expresó muy especialmente en aquellos que emprendieron la misión histórica de encauzar la vida de estas naciones en el período posterior a las revoluciones de independencia. Fue así que los caudillos que se hicieron con el poder se diseñaron "sus" naciones en la misma medida en que les fue suficiente su poderío e influencias. A pesar de la firma de decretos y leyes que tendían a propiciar el desestancamiento social de los grupos más desfavorecidos, los proyectos reales de desarrollo, donde los hubo, no contempló la participación protagónica de indios, negros o campesinos, que por demás desempeñaron un rol significativo en la gesta de la independencia ${ }^{18}$.

“[...] las capitales de corbatín dejaban en el zaguán al campo de botade-potro, o los redentores bibliógenos no entendieron que la revolución que triunfó con el alma de la tierra, desatada a la voz del salvador, con el alma de la tierra había de gobernar, y no contra ella ni sin ella,-entró a padecer América, y padece, de la fatiga de acomodación entre los elementos discordantes y hostiles que heredó de un colonizador despótico y avieso, y las ideas y formas importadas que han venido retardando, por su falta de realidad local, el gobierno lógico. El continente descoyuntado durante tres siglos por un mando que negaba el derecho del hombre al ejercicio de su razón, entró, desatendiendo o desoyendo a los ignorantes que lo habían ayudado a redimirse, en un gobierno que tenía por base la razón; - la razón de todos en las cosas de todos, y no la razón universitaria de unos sobre la razón campestre de otros. El problema de la independencia: no era el cambio de formas, sino el cambio de espíritu"19.

Prejuicios, valores adquiridos en la nebulosa vida colonial conjugados con la adquisición de una cultura extranjeriza envilecida en la vida de las ciudades capitales que desdeñaba al hombre natural y veía en la naturaleza sólo una fuente de obtención de abultadas y rápidas ganancias ocasionó que la verdadera libertad para la totalidad de los latinoamericanos por la fecha fuera un tema pospuesto o mal entendido. De ahí que la colonia continuara existiendo en la república. Se requería un cambio de esencias y no sólo de formas. ${ }^{20}$

\footnotetext{
José Martí Pérez, Nuestra América, 22-24

José Martí Pérez, Nuestra América, 19-20.

José Martí Pérez, Nuestra América.
} 
En tal sentido el conocimiento de la verdadera historia de nuestra América mestiza, se presenta como una condición esencial para entender su identidad, su esencialismo y autenticidad como grupo humano, como cultura y como agente de su propio desarrollo e independencia. En este proceso las ideas sobre la educación y la cultura resultan un elemento básico para penetrar en la significación de este ensayo como hecho cultural e intelectual a fines del siglo XIX.

\section{Nuestra América como plataforma conceptual para la educación y la cultura. Su centro y finalidad}

Nuestra América establece pautas que resultan básicas para la política, la cultura, la educación el arte y el pensamiento social. El centro del ensayo se encuentra en armonía con los mejores empeños, esfuerzos y objetivos a los que José Martí dedicó su vida: la verdadera independencia del continente. La gesta épica de la revolución latinoamericana del XIX no había traído las libertades esenciales para el hombre, razón por la cual el Apóstol concibió un proyecto cultural liberador para el área, que incluyó en su última etapa de vida la lucha por la libertad de Cuba y Puerto Rico. Su determinación quedó expresada, en el cuerpo de este ensayo, cuando afirmó: "Con los oprimidos había que hacer causa común, para afianzar el sistema opuesto a los intereses y hábitos de mando de los opresores." ${ }^{21}$ Su toma de posición al lado de los pobres, o con los pobres, y a favor de la unidad de todos tuvo claras inclinaciones desde su niñez. La etapa que escribió Nuestra América es la expresión de una firme convicción a la que ha dedicado su vida. En tal sentido la declaración arriba citada es apreciada como el centro vital que rige y cohesiona el discurso del ensayo ${ }^{22}$. Para Martí, la unidad es un aspecto vital en nuestros proyectos liberadores ${ }^{23}$, al mismo tiempo que la oposición cerrada a los opresores ha de manifestarse también y de forma efectiva en la cultura, en la tribuna, en la prensa y en todos los espacios y formas en que sea posible mostrarnos cómo somos. Confirma lo dicho esta otra idea: "[...] si la república no abre los brazos a todos, y adelanta con todos, muere la república" ${ }^{24}$.

El proyecto cultural liberador martiano se establece sobre la base de la determinación de nuestros orígenes como grupo humano, es preciso saber quiénes somos, de dónde venimos, qué lugar ocupamos en el concierto de

${ }^{21}$ José Martí Pérez, Nuestra América.

22 Ramón De Armas. "Como quienes van a pelear juntos. Acerca de la idea de unidad continental en "Nuestra América" de José Martî". En Anuario del Centro de Estudios Martianos. No. 11. La Habana: Centro de Estudios Martianos, 1991, 201-214

23 José Martí Pérez, Nuestra América. (Edit. Cit. 2000), 20.

24 José Martí Pérez, Nuestra América. (Edit. Cit. 2000), 24. 
las naciones, cuáles son nuestros desafíos. Estas interrogantes ya habían ocupado el pensamiento de importantes figuras del ámbito latinoamericano. Con meridiana claridad, Martí se refirió a la identidad latinoamericana.

El signo identitario más significativo para el Apóstol fue el mestizaje..$^{25}$ Para él mestizaje es esencia, más allá de las formas que puedan también evidenciar el rasgo. No es una expresión casual, superficial ni advenediza. Confirma que la mezcla caprichosa y variada de hombres y culturas que convergen, algunas de manera forzosa, en esta parte del mundo como expresión del proceso de colonización trajo como resultado un hombre nuevo que no era español, no era africano y tampoco era enteramente deudor a sus antecesores naturales del continente. Observó críticamente la raigambre del pasado: "Éramos una visión, con el pecho de atleta, las manos de petimetre y la frente de niño. Éramos una máscara, con los calzones de Inglaterra, el chaleco parisiense, el chaquetón de Norte-América y la montera de España. El indio, mudo, nos daba vueltas alrededor, y se iba al monte, a la cumbre del monte, a bautizar sus hijos. El negro, oteado, cantaba en la noche la música de su corazón, solo y desconocido, entre las olas y las fieras.

El campesino, el creador, se revolvía ciego de indignación contra la ciudad desdeñosa, contra su criatura. Éramos charreteras y togas, en países que venían al mundo con la alpargata en los pies y la vincha en la cabeza [...]"26. Más adelante expresó: "Ni el libro europeo, ni el libro yankee, daban la clave del enigma hispanoamericano" 27 . Sin embargo, el mestizo autóctono es un resultado original y auténtico del proceso histórico y cultural que aconteció en esta parte del mundo, por ende originales y creativas han de ser sus expresiones culturales. "Por entre las razas heladas y las ruinas de los conventos y los caballos de los bárbaros se ha abierto paso el americano nuevo [...]"28.

Para el Apóstol el contenido de la educación y la cultura debe privilegiar los temas americanos como un modo de educar la identidad y no formar ciudadanos desdeñosos de su ser porque llevan consigo en franco desacomodo con su pueblo y con su tiempo un alma extranjeriza. El remedio lo señala en las páginas de Nuestra América: "Conocer el país, y gobernarlo conforme al conocimiento, es el único modo de librarlo de tiranías. La universidad europea ha de ceder a la universidad americana. La historia de América, de los incas acá, ha de enseñarse al dedillo, aunque no se enseñe la de los arcontes de Grecia.

\footnotetext{
25 " $[\ldots]$ nuestra América mestiza $[\ldots], 19$.

José Martí Pérez, Nuestra América. (Edit. Cit. 2000), 22-23.

José Martí Pérez, Nuestra América. (Edit. Cit. 2000), 23.

José Martí Pérez, O. C. (Edit. Cit. 1963), T. VI. 139.
} 
Nuestra Grecia es preferible a la Grecia que no es nuestra. Nos es más necesaria. Los políticos nacionales han de reemplazar a los políticos exóticos"29.

Resulta vital para Martí el conocimiento del país, conocerlo en sus hechos y relaciones, su naturaleza, historia, cultura y sociedad. Cómo han de llegar a la escena, a la literatura o a la academia los temas nacionales si los creadores no conocen su país. Resulta necesario que la labor creadora y los espacios educativos y sociales sean frecuentados por ideas originales y fieles a nuestra razón de ser. Reclama tener referencias culturales bien claras que brinden cohesión, sentido y significado a los empeños creadores: "Injértese en nuestras repúblicas el mundo; pero el tronco ha de ser el de nuestras repúblicas" 30 . Los pueblos han de vivir en un intercambio constante y fecundo de ideas pero para poder confrontar con el mundo ha de existir un "tronco" propio que sirva de asidero intelectual a quienes se empeñan en esas complejas labores. En tal sentido es importante también internacionalizar e intercambiar de forma frecuente nuestras ideas y realizaciones. Reclamó: “[...] el deber urgente de nuestra América es enseñarse como es, una en alma e intento, vencedora veloz de un pasado sofocante[...]"31.

La fijación conceptual de los aspectos identitarios que define el ensayo resultan trascendentes en lo relacionado con las mejores prácticas en la enseñanza y las teorías que la nutren. Ser hombre significa tener que educarse, pero ese proceso ha de ser conducido de forma creadora y en correspondencia con la época y aspiraciones de las naciones. Los estudios de la psicología recomiendan técnicas para el trabajo en grupo, así como otros temas relacionados con la motivación por el estudio y la fijación del conocimiento con mayor solidez, todo ello es válido. Martí estaba convencido de la singularidad del hombre latinoamericano y esa singularidad requiere formas particulares de enseñar y de aprender. En México, expresó: “[...] las naturalezas americanas, necesitan de que lo que se presente a su razón tenga algún carácter imaginativo; gustan de una locución vivaz y accidentada; han menester que cierta forma brillante envuelva lo que es en su esencia árido y grave. No es que las inteligencias americanas rechacen la profundidad; es que necesitan ir por un camino brillante hacia ella"32.

La locución "vivaz y accidentada" sería la forma fiel de lograr una comunicación efectiva entre el que enseña y los que aprenden. Así el acto

29 José Martí Pérez, Nuestra América. (Edit. Cit. 2000), 17. Este es un elemento esencial para el gobierno, para concebir la educación del pueblo. "... las formas de gobierno de un país han de acomodarse a sus elementos naturales..."

30 José Martí Pérez, Nuestra América, 17.

31 José Martí Pérez, Nuestra América, 27.

32 José Martí Pérez, O. C. (Edit. Cit. 1963), T. VI. 235. 
educativo tendrá mejores resultados. Se logrará un mejor aprendizaje y una implicación afectiva en dicho proceso. Esto sería una forma de tomar en cuenta la naturaleza americana, su riqueza y brillantez en sus expresiones ambientales y espirituales.

\section{CONCLUSIÓN}

La reflexión actual sobre "nuestra América" permite establecer para qué enseñar, qué enseñar, cómo hacerlo, con qué medios hacerlo y cómo establecer el fecundo nexo educación-tradición-historia-cultura como un modo de aunar esfuerzos los que se dedican al complejo mundo de enseñar, educar, mostrar el mundo de la creación y al mismo tiempo facilitar la creación y el enriquecimiento de la cultura.

"Nuestra América" es un hito en la obra martiana como expresión de la madurez de su pensamiento, es también un hito en la historia del pensamiento y la cultura Latinoamericana en tanto representa un discurso coherente y fundador de nuestra imagen, de nuestra mejor imagen, en la que caben mezclados los héroes de siempre, levantados sobre las cabezas de cientos de miles de campesinos e indios, que juntos han presentado a esta América dolorosa, mestiza y digna al mundo.

\section{REFERENCIAS}

Alberdi, Juan Bautista. Ideas para presidir la confección del curso de Filosofía contemporánea. En: Pensamiento positivista latinoamericano. Tomo I. Compilación. Prólogo y cronología Leopoldo Zea. Caracas: Biblioteca Ayacucho. 1980:61 - 67.

Ballón, José. Autonomía cultural americana: Emerson y Martí. Madrid: Ed. Pliegos, 1986.

Chávez Rodríguez, Justo A. "Filosofía y Educación en América Latina”. Educación. No. 85. La Habana: may - agost. (1995):14-17.

De Armas, Ramón. "Como quienes van a pelear juntos. Acerca de la idea de unidad continental en "Nuestra América" de José Martí". En Anuario del Centro de Estudios Martianos. No. 11. La Habana: Centro de Estudios Martianos, 1991,201-214

De Armas, Ramón. "José Martí: educación para el desarrollo". En Letras. Cultura en Cuba. / Prefacio y comp. Ana Cairo Ballester. La Habana, Editorial Pueblo y Educación, 1989:261-275

Escribano Hervis, Elmys. El Concepto de "nuestra América" en la obra de José Martí. (Apuntes esenciales), - en Avanzada Cientifica. - Vol. 1. No 2. - Matanzas, 1998. -

Escribano Hervis, Elmys. La concepción de la educación en la obra de José Martí. La Habana: Edit. Pueblo y Educación, 2006.

Fernández, Julio. "La Organización del Estado en "Nuestra América", en Anuario del Centro de Estudios Martianos. No. 11. La Habana: Centro de Estudios Martianos, 1991. 
Fernández Retamar, Roberto. Calibán y otros ensayos: Nuestra América y el mundo, La Habana: Ed. Arte y Literatura, 1979.

Fernández Retamar, Roberto. El Credo independiente de América Latina. La Habana: Ed. Abril, 1992.

Fernández Retamar, Roberto. Todo Calibán. La Habana: Fondo Cultural del ALBA, 2006.

Galeano, Eduardo. Memoria del fuego: II Las Caras y las máscaras. La Habana: Ed. Casa de las Américas. (Colección Honda), 1990

García Godoy, F. Americanismo literario. Madrid, Editorial América. (Biblioteca Andrés Bello), s.a.

Guadarrama, Pablo. "Martí dentro del concepto latinoamericano de humanismo", en Revolución y Cultura. No. 3. La Habana, (1995): 10-17.

Guadarrama, Pablo. Humanismo y autenticidad en el pensamiento latinoamericano. Santa Clara: Cuba: Bogotá: Colombia: Unidad Editorial - UNED, 1997.

Guadarrama, Pablo. "Humanismo práctico y desalienación en José Martí”, en José Martí 1895 1995. Literatura - Política - Filosofía - Estética. Editores Otmar Ette y Titus Hey denreich. Frankfurt is Main: Universität Erlangen - Nürnberg -Veruvent Verlag, 1994.

Hidalgo Paz, Hibraín. Incursiones en la obra de José Martí. La Habana, Editorial Ciencias Sociales: Centro de Estudios Martianos, (Colección de Estudios Martianos), 1989.

Jean Lamore. Historia y "biología” en la "América mestiza” de José Martí, en Anuario del Centro de Estudios Martianos. No. 2. La Habana: Centro de Estudios Martianos, 1979:92 - 110.

Lezama Lima, José. Imagen de América Latina. Caracas, Universidad Central de Venezuela. Fac. de Humanidades y Educación, (Memoria de América Latina),1988.

Martí Pérez, José, En las entrañas del monstruo./sel., introd., y notas del Centro de Estudios Martianos. La Habana, Editorial de Ciencias Sociales, 1984.

Martí Pérez, José. La Edad de Oro. La Habana: Editorial Gente Nueva, (s.a.)

Martí Pérez, José. Nuestra América. Edición crítica. Investigación, presentación y notas Cintio Vitier. La Habana: Centro de Estudios Martianos, 2000.

Martí Pérez, José. Obras Completas. La Habana: Ed. Nacional de Cuba, 1963. (28 t.)

Martí Pérez, José. "Revolución en la enseñanza”, en Anuario del Centro de Estudios Martianos. No. 8. La Habana, 1985: 14-19.

Martí Pérez, José. "Una novedad en educación pública”, en Anuario del Centro de Estudios Martianos. No. 2. La Habana, 1979:19-20.

Martínez Heredia, Fernando. "Nuestra América el presente y el proyecto de la América Latina", en Anuario del Centro de Estudios Martianos. No. 11. La Habana: Centro de Estudios Martianos, 1991:177- 189.

Mentor Interactivo Enciclopedia de Ciencias Sociales. Barcelona (España): Edit. Océano. (s. a.)

Montiel, Edgar. "Educación para la identidad", en Educación. No. 85, mayo - agosto, 1995: 31 44.

Muñoz González, Roberto. Cultura y desarrollo en "Nuestra América", de José Martí: una lecturades de nuestros tiempos, en Anuario del Centro de Estudios Martianos. No. 24. La Habana: Centro de Estudios Martianos, 2001: 226 - 236.

Rodríguez, Carlos Rafael. "José Martí, anticipador de nuestro tiempo", en Anuario del Centro de Estudios Martianos. No. 14. La Habana, 1991:143-150. 
Rodríguez, Pedro Pablo. De las dos américas. (Aproximaciones al pensamiento martiano.) La Habana, Centro de Estudios Martianos, 2010.

Rodríguez, Pedro Pablo. "En el fiel de América. El concepto de identidad latinoamericana de José Martí y las Antillas hispánicas”, en Revolución y Cultura, No. 3, La Habana, (1995): 5-9.

Rodríguez, Pedro Pablo. "Formación del pensamiento latinoamericanista de José Marti", en Anuario del Centro de Estudios Martianos. No. 2, La Habana: Centro de Estudios Martianos, 1979: $135-148$.

Rodríguez, Pedro Pablo. "La idea de la liberación nacional en José Marti”, en Anuario del Centro de Estudios Martianos. No. 4. La Habana, 1982:169-214.

Rodríguez, Pedro Pablo. Las Imágenes de Nuestra América. La Habana: Edit. Casa Editora Abril, 1991.

Rodríguez, Pedro Pablo. "Martí en Venezuela: la fundación de nuestra América", en Anuario del Centro de Estudios Martianos. No. 12. La Habana, 1989:133-174.

Rodríguez, Pedro Pablo. "Nuestra América como programa revolucionario", en Anuario del Centro de Estudios Martianos. No. 14, La Habana: Centro de Estudios Martianos, 1991: 215 - 225.

Roig De Leuchsenring, Emilio. La República de Martí. - 4ª edición notablemente aumentada, La Habana, 1958.

Sarmiento, Domingo Faustino. Conflictos y armonías de las razas en América Latina, en: Pensamiento positivista latinoamericano. Tomo I. Compilación. Prólogo y cronología Leopoldo Zea. Caracas: Biblioteca Ayacucho. 1980: 106 - 142.

Sarmiento, Domingo Faustino. Facundo. (Introducción de Noé Jitrik) Caracas: Biblioteca Ayacucho. S. A.

Schulman, Ivan A. Relecturas martianas: narración y nación., Amsterdan, Editorial Amsterdan Atlanta, G.A.1994.

Serrano Calderón De Ayala, Emilio. "La cruz y la patria", en Indios y criollos: (Lecturas para cualquier criollo). La Habana, Editorial Casa de las Américas, 1992:234-265.

Suárez Franceschi, Arsenio. América en Martí. La Habana, Editorial Academia, 1998.

Vitier, Cintio. Ese sol del mundo moral: para una historia de la eticidad cubana. La Habana: Ed. Unión, 1995.

Vitier, Cintio. Las imágenes en "Nuestra América", en Anuario del Centro de Estudios Martianos. No. 14, La Habana: Centro de Estudios Martianos, 1991: 160 - 166

Vitier, Cintio. "Martí: el heredero, el agonista, el guía", en Educación. No. 82. La Habana, may. - agost. 1994: 54-59.

Vitier, Cintio. Temas martianos. - $2^{a}$ serie. La Habana: Centro de Estudios Martianos. Editorial Letras Cubanas, 1982.

Weinberg, Gregorio. Modelos educativos en el desarrollo histórico de América Latina. Buenos Aires: UNESCO, 1981.

Zea, Leopoldo. "La Cultura latinoamericana y su sentido libertario", en Problemas 4. Identidad latinoamericana. Enfoques filosófico - literarios. Sel. Enrique Ubieta Gómez. La Habana: Ed. Academia, 1994.

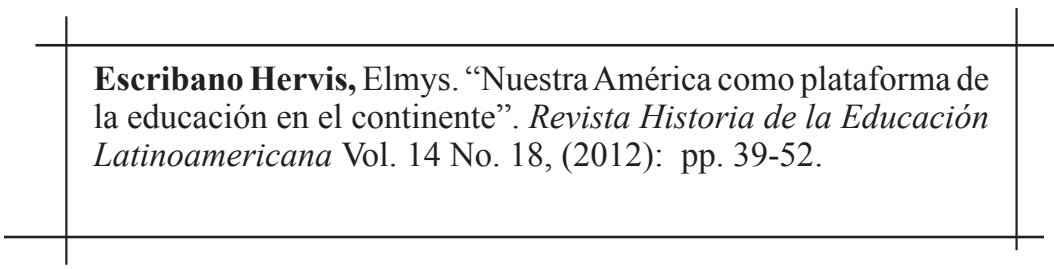

